\title{
STUDY OF POSSIBLE RELATION BETWEEN THYROID VOLUME, NODULE FORMATION AND GLUCOSE METABOLISM DISORDERS IN EGYPTIAN POPULATION
}

\author{
By \\ MANAL MOHSEN ${ }^{1}$, ALYAA AHMED EL-SHERBENY ${ }^{2 *}$, AHMED MOHAMED \\ BAHAA EL-DIN ${ }^{2}$, EMADABD EL-MOHSENABD EL-HADI ${ }^{2}$, \\ And MAHMOUD MOUSTAFA NAFIE ${ }^{3}$ \\ Departments of Clinical Pathology ${ }^{1}$, Internal Medicine ${ }^{2}$, and, Surgery ${ }^{3}$, \\ Faculty of Medicine, Ain Shams University, Cairo 11566, Egypt \\ ( ${ }^{*}$ Correspondence: draliaa78@yahoo.com)

\begin{abstract}
\end{abstract}
Insulin resistance (IR) with compensatory hyper-insulinemia are key factors involved in the pathogenesis of glucose metabolism disorders (including impaired fasting glucose and glucose tolerance and frank diabetes mellitus) as well as increased thyroid gland volume and nodule prevalence in patients with metabolic syndrome. On the other hand, thyroid hormone contributes to the regulation of carbohydrates metabolism and pancreatic function.

This cross-sectional study investigated the possible association between the different glucose metabolic disorders (GM) and thyroid gland volume. The study was conducted on 400 subjects over one year duration, divided into $50 \%$ diabetic patients in comparison to $25 \%$ pre-diabetics and $25 \%$ cross-matched control. All the subjects were investigated by fasting and postprandial blood sugar and fasting insulin level (for HOMA-IR calculation) as well as TSH assay combined with thyroid ultrasound.

The results showed that thyroid volume was significantly larger in patients with diabetes compared to the control as well as significant positive correlation between thyroid volume and FBS, fasting insulin, HOMA-IR, 2hours pp BS and HbA1cin. Besides, there was significant association between serum TSH levels and thyroid volume. The main regulator of thyroid cell growth and differentiation is TSH. The elevated insulin levels due to IR lead to an increase in IGF-1 levels (which is an important hypertrophic and progression factor for a series of cell types including thyroid cells with increased risk of malignancy in such patients).

Key words: Egypt, Diabetic patients, Thyroid volume, Glucose metabolism, Insulin resistance.

\section{Introduction}

Insulin resistance (IR) is known to be characteristic of type 2 diabetes mellitus, and is regarded as an important mechanism in disease pathogenesis. One of the key pathogenetic mechanisms of IR progression is impaired free fatty acid (FFA) metabolism. Plasminogen-activator inhibitor 1 (PAI-1) and key inflammation markers, i.e., interleukin 6 (IL-6) and C-reactive protein (CRP), also play a role (Yu et al, 2011). IR in general and diabetic populations is associated with cardiovascular risk factors including hyperglycemia, dyslipoproteinemia, arterial hypertension, obesity, thrombosis, and smoking (Gruzdeva et al, 2013). IR is associated with increased thyroid gland volume and thyroid nodule prevalence in patients with metabolic syndrome. Data on the association of thyroid morphology and abnormal glucose metabolism are limited $(\mathrm{Cu}-$ neyd et al, 2013). Thyroid volume enlargement and the prevalence of thyroid nodules were higher in patients with insulin resistance. A relationship between thyroid volume, nodule formation and glucose metabolism disorders (GMD) was not yet clarified (Duran et al, 2014).

The thyroid gland is a large ductless gland in the neck which secretes hormones regulating growth and development through the rate of metabolism. The thyroid volume was influenced by multiple factors such as iodine supply and deficiency, age, sex, body surface area (BSA), body mass index (BMI), smoking and genetic factors (Gharib and Papini, 2007; Zou, et al, 2013).The impaired fasting glucose (IFG), the impaired tolerance 
(IGT), and frank diabetes mellitus (DM) being considered among the principal disorders of the glucose metabolism where insulin resistance (IR) acted as a significant causative factor (Rezzonico, et al, 2008).

The morphological and pathological changes in the thyroid gland induced by glucose metabolism disorders (GMD) increased thyroid gland volumes in patients with IR (Ayturk, et al, 2009). Insulin resistance is associated with GMD and it is well known that, in the pathogenesis of DM, insulin resistance and compensatory hyper-insulinemia play a pivotal role (American Diabetes Association, 2008).

The aim of this study was to investigate the possible association between the different glucose metabolic disorders and the thyroid gland volume.

\section{Subjects and Methods}

Study design: This is a cross sectional study conducted on 400 patients selected from the out-patients'clinic of Endocrinology and Diabetes, Ain Shams University Hospitals, from January 2016 to January 2017. They were divided into the following groups: G1: included 200 patients with T2DM, G2: included 100 patients with prediabetes state either impaired fasting glucose or impaired glucose tolerance, and G3: included healthy cross-matched 100 individuals as a control. All groups were divided equally regarding both sexes. All were subjected to full history taking and general clinical examination.

Inclusions criteria: Adult male and female patients above the age of 25 years proven to have T2DM or pre-diabetes state.

Exclusion criteria: 1- Patients with T1DM or known to have any other endocrinopathies or autoimmune diseases, and 2- History of neck irradiation, operation or fine-needle aspiration biopsy (FNAB), a history of thyroid disease, overt or subclinical hypothyroidism and previous-thyroxine suppression therapy at any time.

Laboratory investigation: 1- Fasting and postprandial blood sugar then all subjects were classified according to the American Diabetes Association (ADA, 2008) criteria (ADA, 2010). The categories of fasting plasma glucose (FPG) values were as follows: FPG $<100 \mathrm{mg} / \mathrm{dL}$ was a normal fasting glucose; FPG 100-125 mg/dL was IFG and $\mathrm{FPG} \geq 126 \mathrm{mg} / \mathrm{dL}$ defines diagnosis of diabetes. The corresponding categories when the oral glucose tolerance test (OGTT) was used as followed: 2-h post-load glucose $<140 \mathrm{mg} / \mathrm{dL}$ was a normal glucose tolerance; 2-h post-load glucose 140-199mg/dL defines IGT and 2-h post-load glucose $\geq 200 \mathrm{mg} / \mathrm{dL}$ defines diagnosis of diabetes. According to the fasting blood glucose and OGTT, patients were classified into: Patients with normal blood glucose, patients with prediabetes (IFG \& IGT) and patients with DM. Also, assessment of glycosylated hemoglobin and fasting insulin was used for calculation of HOMA-IR.

2- Assay of TSH by chemiluminescence immune assay: This was done on a fully automated Cobas-e411 (Roche Diagnostics GmbH, Sandhofer-Strasse, Mannheim, Germany) using instrument's manufacturer reagents. TSH assay was a sandwich immunoassay using a biotinylated TSH antibody and a ruthenium-labeled TSH-specific antibody for capturing and detection respectively. TSH standard reference range was 0.27-4.2 $\mu$ $\mathrm{IU} / \mathrm{ml}$; intra-assay coefficient of variation (CV), 1.5\%-8.6\% and inter-assay CV, 1.8\%$8.7 \%$

3- Homeostasis model assessment (HOMA) Score to determine Insulin resistance (IR): It is calculated using the formula: Homeostasis model assessment HOMA Score $=[$ Fasting glucose $(\mathrm{mg} / \mathrm{dL}) \mathrm{x}$ fasting insulin $(\mathrm{mU} / \mathrm{L})] /$ 405.I.R. was considered to be present in cases with HOMA $\geq 3.0$ (Matthews et al, 1985).

Radiological Assessment: Thyroid volume was estimated by the ultra-sonography using a $10-\mathrm{MHz}$ linear probe (Logiq 5 Pro, GE, Medical Systems, WI, USA). The volumes of the thyroid glands and nodules were cal- 
culated according to the ellipsoid formula: volume $(\mathrm{mL})=$ depth $\mathrm{x}$ width $\mathrm{x}$ length $(\mathrm{cm})$ $\mathrm{x} \pi / 6$. Nodules were defined as solitary lesions distorting the uniform shape or echo pattern of the thyroid gland with a diameter of at least $1 \mathrm{~cm}$. The volume of nodules was not considered together with thyroid volumes.

Informed consent: Informed consent was obtained from all the participants included.

Ethical approval: Ethical approval was obtained from Ain Shams University, Faculty of Medicine; Research Ethics Committee (FWA00017858).

Statistical analysis: Data were analyzed by using PASW version 18 (IBM@ Corp., Armonk, NY, USA). Normality rate was tested using D'Agostino-Pearson test, normally distributed numerical variables were presented as mean $\pm \mathrm{SD}$, non-normally distributed data were presented as median and interquartile range. Numerical data were compared using Kruskal-Wallis test, with post hoc boneferroni testing, and data were given in tables using subscripts (APA style), qualitative data were compared using chi-square $t$ test, or Fisher exact test. Correlations were done using Spearman's coefficient. Multivariate linear regression analysis was done to estimate independent predictors of thyroid volume. Significant results were graphically illustrated, $\mathrm{P}<0.05$ within a confidence interval of $95 \%$ were deemed as significant.

\section{Results}

The results are shown in tables $(1,2,3,4$, $\& 5)$ and figures $(1 \& 2)$.

Table 1: Demographic data in studied groups

\begin{tabular}{|c|c|c|c|}
\hline Subject condition & DM & Pre-Diabetes & Normal \\
\hline Age in years & $52.18 \pm 8.62$ & $51.43 \pm 9.83$ & $47.88 \pm 11.09$ \\
\hline Male & $114(57 \%)$ & $47(47 \%)$ & $57(57 \%)$ \\
\hline Female & $86(43 \%)$ & $53(53 \%)$ & $43(43 \%)$ \\
\hline
\end{tabular}

Table 2: Descriptive metabolic parameters in studied groups

\begin{tabular}{|c|c|c|c|}
\hline Subject condition & DM & Pre-Diabetes & Normal \\
\hline FBS (mg/dl) & $206.72 \pm 60.86$ & $109.81 \pm 12.02$ & $83.97 \pm 8.86$ \\
\hline Fasting Insulin (micIU/ml) & $9.05 \pm 5.08$ & $15.35 \pm 4.69$ & $11.18 \pm 3.95$ \\
\hline HOMA-IR & $4.49 \pm 2.85$ & $4.10 \pm 1.32$ & $2.26 \pm .80$ \\
\hline 2 hour PP BS (mg/dl) & $257.23 \pm 52.57$ & $167.30 \pm 18.64$ & $121.58 \pm 8.52$ \\
\hline HBA1C (\%) & $9.07 \pm .89$ & $6.02 \pm .37$ & $5.01 \pm .34$ \\
\hline TSH (micIU/ml) & $2.12 \pm .92$ & $2.63 \pm 1.09$ & $2.24 \pm 1.07$ \\
\hline
\end{tabular}

Table 3: Comparison between groups regarding thyroid volume and maximal nodule dimension

\begin{tabular}{|l|l|l|l|l|}
\hline & DM & Pre-Diabetes & Normal & P Value \\
\hline Thyroid Volume $(\mathrm{ml})$ & $6.8(6.4 \pm 11)_{\mathrm{a}}$ & $6.6(6.4 \pm 7.5)_{\mathrm{a}, \mathrm{b}}$ & $6.6(6.4 \pm 7.4)_{\mathrm{b}}$ & $<0.001$ \\
\hline Nodule max dimension $(\mathrm{mm})$ & $10(8.5 \pm 12)_{\mathrm{a}}$ & $9.5(7 \pm 12)_{\mathrm{a}}$ & $8(7 \pm 12)_{\mathrm{a}}$ & 0.484 \\
\hline
\end{tabular}

Values in same row not shared same subscript $=$ significantly different in boneferroni post-hoc analysis; Data as median (inter-quartile) range.

Table 4: Correlation between thyroid volume and other parameters:

\begin{tabular}{|l|c|c|}
\hline \multirow{2}{*}{ Variants } & \multicolumn{2}{|c|}{ Thyroid Volume (ml) } \\
\cline { 2 - 3 } & $\mathrm{R}$ & P value \\
\hline Age(Years) & -0.132 & 0.008 \\
\hline FBS (mg/dl) & 0.149 & 0.003 \\
\hline Fasting Insulin (micIU/ml) & 0.199 & $<0.001$ \\
\hline HOMA & 0.313 & $<0.001$ \\
\hline 2 hour PP BS (mg/dl) & 0.148 & 0.003 \\
\hline HBA1C (\%) & 0.177 & $<0.001$ \\
\hline TSH (micIU/ml) & 0.010 & .850 \\
\hline
\end{tabular}

Table 5: Multivariate linear regression analysis for predictors of thyroid volume:

\begin{tabular}{|l|c|c|}
\hline variants & $\beta$ & P value \\
\hline Age & -.069 & 0.117 \\
\hline FBS $(\mathrm{mg} / \mathrm{dl})$ & -.342 & 0.011 \\
\hline Fasting Insulin (micIU/ml) & -.270 & 0.015 \\
\hline HOMA & .761 & $<0.001$ \\
\hline 2 hour PP BS (mg/dl) & .095 & 0.393 \\
\hline HBA1C $(\%)$ & .098 & 0.25 \\
\hline
\end{tabular}




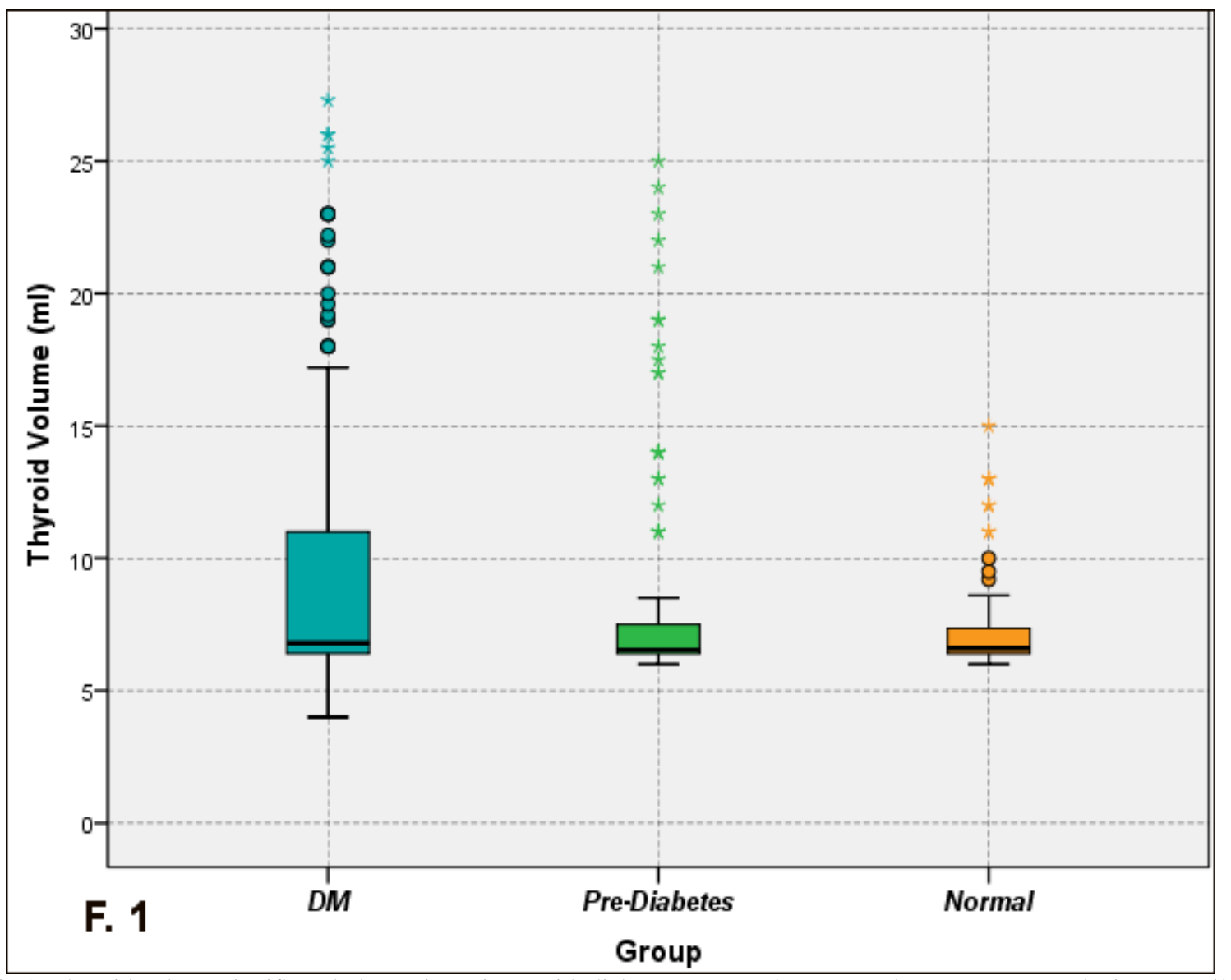

Fig.1: Thyroid volume significantly larger in patients with diabetes compared to $t$ control. Box represents the interquartile range. Horizontal line inside the box represents the median. Whiskers represent minimum and maximum values excluding outliers (rounded markers) and extreme observations (asterisks).

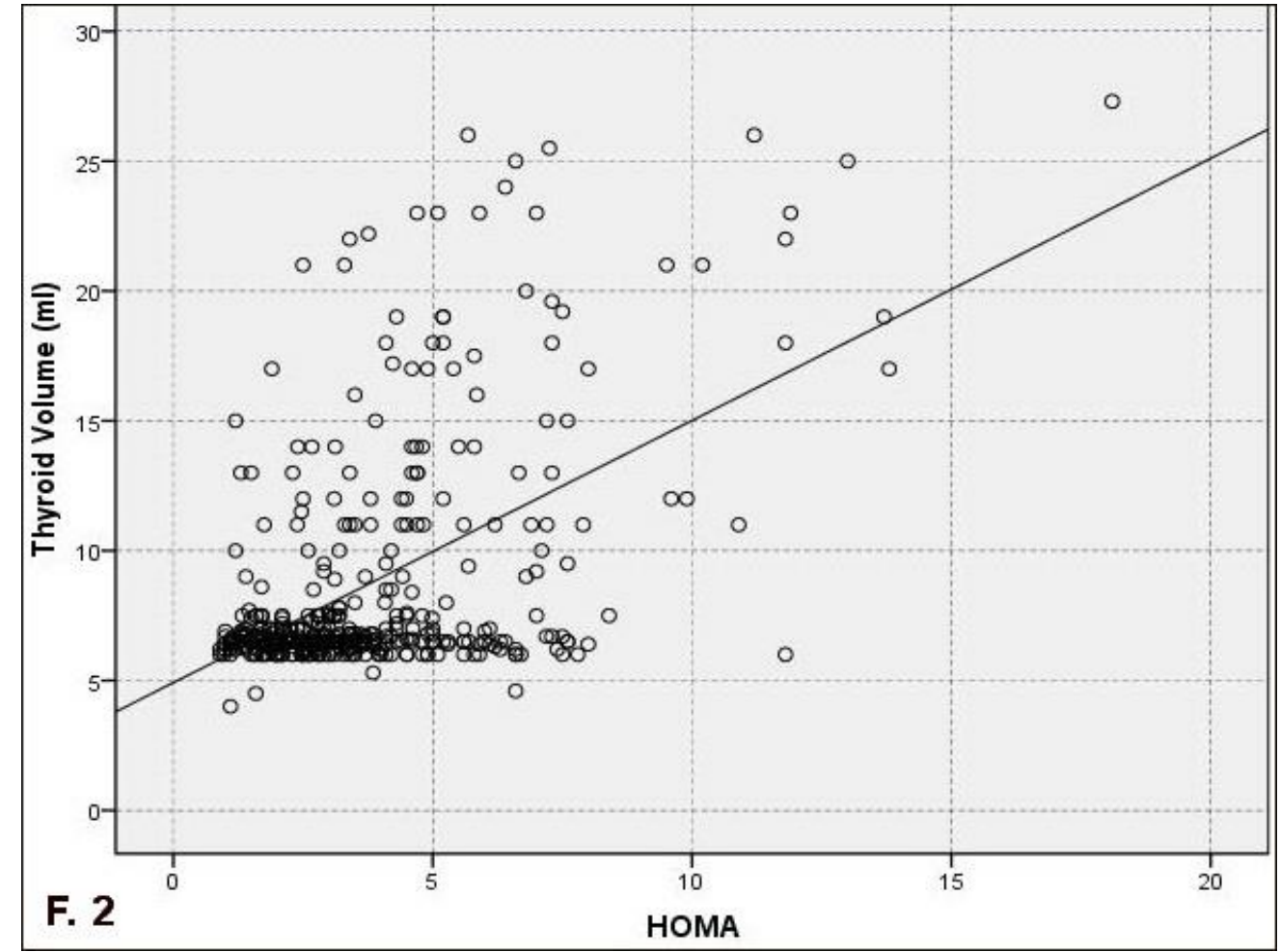

Figure 2: Significant positive correlation between thyroid volume and HOMA-IR 


\section{Discussion}

In the present study, the mean age for the diabetic group was $52.18 \pm 8.62$ years, for pre-diabetes group was $51.43 \pm 9.83$ years and for control was $47.88 \pm 11.09$ years. Also, the males in diabetic group were 114/200 (57\%) while females were $86 / 200$ (43\%), but in males' pre-diabetes group were $47 \%$, females were $53 \%$ and in control group males were $57 \%$ and females were $53 \%$.

In the present study, the mean FBS in diabetic patients was $206(72 \pm 60.86 \mathrm{mg} / \mathrm{dl})$ while in the pre-diabetics group was 109 $(81 \pm 12.02 \mathrm{mg} / \mathrm{dl})$ and in the control was $83.97 \pm 8.86 \mathrm{mg} / \mathrm{dl}$. Also, the fasting insulin level was higher in the pre-diabetic group than the control; $15.35 \pm 4.69 \mathrm{micIU} / \mathrm{ml}$ and $11.18 \pm 3.95 \mathrm{micIU} / \mathrm{ml}$ respectively, as compared to the established diabetes; $9.05 \pm 5.08$ $\mathrm{micIU} / \mathrm{ml}$.

Besides, HOMA-IR was higher in diabetics than pre-diabetic group, $4.49 \pm 2.85$ and $4.10 \pm 1.32$ respectively and both were higher than in control $2.26 \pm 0.80$. Thus, other glucose metabolic parameters were higher in diabetics than pre-diabetic group while these parameters were within normal range in the control group. No doubt, the thyroid hormone contributed to the regulation of $\mathrm{CHO}$ metabolism and pancreatic function and on the other hand, diabetes affects thyroid function tests to variable extents (Canaris et al, 2000; Dultz et al, 2009).

Thyroid hormones are critical determinants of brain and somatic development in infants and of metabolic activity in adults; they also affect the function of virtually every organ system. Thyroid hormones must be constantly available to perform these functions (Oetting and Yen, 2007). Thyroid hormones affect glucose metabolism via several mechanisms during hyperthyroidism, the half-life of insulin is reduced due to increased rate of degradation of biologically inactive insulin precursors (Kawasaki, et al, 2006; Villano et al, 2009). Few high-lighted the relation between the thyroid volume and
GMD, the present study showed also significantly positive correlation between thyroid volume and HOM-IR which agreed with Rezzonico et al. (2008) who found a positive association between IR \& thyroid volume. In the present study, there was significant positive correlation between the thyroid volume, FBS, 2HDD and HOM-IR, with agreed with Duran et al. (2014) who reported significant relation between type $2 \mathrm{DM}$ and thyroid volume among the patient referred to biopsy examination.

The most important effects of GMD leading to elevated risk are hyper-insulinemia, IR, and hyperglycemia that can exist for years before and after diagnosis. Elevated insulin levels due to IR lead to an increase in IGF-1 levels (which is an important hypertrophic and progression factor for a series of cell types including thyroid cells) (Rapp, et al, 2006).Experimental evidence showed that both insulin and IGF-1 modulated the regulation of thyroid gene expression and elevated insulin and/or glucose level may lead to proliferation of thyroid cells by affecting cellular energy metabolism.

Thyroid volume was significantly higher in diabetic patients compared to control $(\mathrm{p}<0.001)$ and a non-significant larger volume in diabetic patients compared to prediabetes ones. On the other hand, there was a non-significant difference between the three study groups with regard to maximal nodule dimension. The size of a nodule or a lobe can be measured fairly accurately based on a scale on the sonographic screen or, with advanced equipment, the sonographer can place marks on the image to calculate the dimensions electronically. One study reported imperfect concordance between the dimensions of thyroid nodules as revealed by ultrasound examination when compared with surgical excision. Concordance was $78.5 \%$ with nodules equal to or smaller of than $1 \mathrm{~cm}$ and significantly less for larger nodules (Deveci et al, 2007). Minimizing differences between the ultrasonographers 
when estimating the size of large goiters or the nodules was reported when curved-array transducers rather than linear-array equipment was employed (Gruzdeva et al, 2013). Rapp et al. (2006) reported that type 1 DM had larger thyroid volume when compared to healthy control group, and Duran et al. (2014) found that TSH level was higher in diabetic patient than the prediabetic and the control group. Progression of the thyroid cell cycle is dependent on jointactivity of TSH and insulin/insulin like growth factor-1 (IGF-1), all of which function as co-mitogenic factors. The main regulator of growth and differentiation of thyroid cell was TSH (Rapoport, et al, 1998; Inoue et al, 2006). Therefore, the serum TSH levels should be evaluated in the initial evaluation of the patient with a high thyroid volume (Riedemann, 2006).

In the present study, there was significant negative correlation with age $(\mathrm{p}<0.008)$, but significant positive correlation was between thyroid volume and FBS, fasting insulin, HOMA-IR, 2hours pp BS \& HbA1C ( $\mathrm{p}=$ $0.003,<0.001,<0.001,0.003,<0.001$ respectively).

Ahmed and Aboelnaga (2015) in Egypt stated that the thyroid cancer represented about $1 \%$ of the new cancer and oestrogen played a role in the pathogenesis of thyroid neoplasm by studying the clinicopathological criteria and ER expression of thyroid cancer in Mansoura University (Egypt), and correlated the survival to these clinicopathological data and ER expression. They concluded that the prognosis of thyroid carcinoma in Egypt was similar to that occurred worldwide. ER- $\alpha$ expression was a significant prognostic marker for DFS in thyroid cancer and can be used as a predictive factor of lymph node metastasis.

Generally speaking, the diabetes mellitus is a public health challenge worldwide, and roughly $25 \%$ of patients with diabetes in developing countries developed at least one foot ulcer during their lifetime (Melmed $e t$ $a l, 2011)$. Global diabetes incidence is in- creasing rapidly; this rise in prevalence of DM is likely to bring a concomitant increase in its complications among diabetic patients. The chronic hyperglycemia of diabetes is associated with long-term damage, dysfunction, and failure of different organs, especially the eyes, kidneys, nerves, heart, and blood vessels (ADA, 2015). The International Diabetes Federation (IDF) predicted that nearly 7.6 million Egyptians would have diabetes by 2025, making it one of the top ten countries in the world regarding the diabetes incidence (Gunaid and Assabr, 2008).

Moreover, Desalu et al. (2011) in Nigeria reported one important complication of DM is the foot problems; these complications constitute an increasing public health problem and are a leading cause of hospital admission, amputation and mortality in diabetic patients El-Tawdy et al. (2016) in Egypt reported that diabetic foot ulcer was the major global and devastating complication of diabetes mellitus that affected at least $20 \%$ of diabetic patients during their lifetime. On the other hand, Metwalley and El-Saied (2014) in Upper Egypt reported high prevalence of thyroid abnormalities in children and in children and adolescents with type 1 diabetes. Besides, Elebrashy et al. (2016) reported that the autoimmune thyroid disease is more common in Egyptian women with the type 2 diabetes than non-diabetic women, and thus points to a role of autoimmunity in the pathogenesis of type 2 diabetes. Consequently, thyroid disease and diabetes mellitus are the two most common endocrine disorders in clinical practice.

\section{Conclusion}

The thyroid is a vitally important hormonal gland that regulates metabolism and growth in the body. When T3 and T4 levels are low in the blood, the pituitary gland releases more TSH to tell the thyroid gland to produce more thyroids.

The outcome results showed a positive correlation between GMD/Type $2 \mathrm{DM}$ and thyroid volume. The thyroid ultrasound is a 
must in the diabetic patients suffering from glucose metabolism disorders.

The authors declared that they neither have potential conflict of interest in this study nor received any financial support

\section{References}

ADA, 2008: (American Diabetes Association) Diagnosis and classification of diabetes mellitus. Diabetes Care 31:S55-60.

ADA, 2010: American Diabetes Association: Nutritional recommendations and principles for people with diabetes mellitus. Diabetes Care Clin. Pract. Recommend. 24:S1-8.

ADA, 2015: Diabetes basics; accessed Food, accessed 28 September.

Ahmed, RA, Aboelnaga, EM, 2015: Thyroid cancer in Egypt: histopathological criteria, correlation with survival and oestrogen receptor protein expression. Pathol. Oncol. Res. 21, 3:793802.

Ayturk, S, Gursoy, A, Kut, A, et al, 2009: Metabolic syndrome and its components are associated with increased thyroid volume and nodule prevalence in a mild-to-moderate iodine-deficient area. Eur. J. Endocrinol. 161:599-605.

Canaris, GJ, Manowtiz, NR, Mayor, G, et al, 2000: The Colorado thyroid disease prevalence study. Arch. Inter. Med. 160, 4:526-34.

Cuneyd, A, Aysen, A, Semra, A, et al, 2013: Impaired glucose metabolism is a risk factor for increased thyroid volume and nodule prevalence in a mild-to-moderate iodine deficient area. Metabol. 62, 7:970-5.

Desalu, OO, Salawu, FK, Jimoh, AK, Adekoya, AO, Busari OA, et al, 2011: Diabetic foot care: Self-reported knowledge and practice among patients attending three tertiary hospital in Nigeria. Ghana Med. J. 45, 2:60-5.

Deveci, MS, Deveci, G, Li-Volsi, VA, et al, 2007: Concordance between thyroid nodule sizes measured by ultrasound and gross pathology examination: effect on patient management. Diagn. Cytopathol. 35:579-84.

Dultz, G, Matheis, N, Dittmar, M, et al, 2009: The protein tyrosine phosphatase non-receptor type $22 \mathrm{C} 1858 \mathrm{~T}$ polymorphism is a joint susceptibility locus for immune-thyroiditis and autoimmune diabetes. Thyroid 19, 2:143-8.

Duran, A, Cuneyd, A, Alptekin, G, et al, 2014: Thyroid volume in patients with glucose metabolism disorders. Arqbras. Endocrinol. Metabol. 58, 8:824-7.
Elebrashy, IN, El Meligi, A, Rashed, L, Salam, RF, Youssef, E, et al, 2016: Thyroid dysfunction among type 2 diabetic female Egyptian subjects. Ther. Clin. Risk Manag. 21, 12:175762.

El-Tawdi, AHF, Ibrahim, EA, Abdallah, ES, Al Sakhawy EMA, Morsy, T A, 2016: Maggot debridement therapy (MDT): It is safe and economic for treating a diabetic foot ulcer. J. Egypt. Soc. Parasitol. 46, 1:223-34.

Gharib, H, Papini, E, 2007: Thyroid nodules, clinical importance, assessment, and treatment. Endocrinol. Metab. Clin. North Am. 36:707-35.

Gruzdeva, O, Uchasova, E, Dyleva, Y, Belik, E, Shurygina, E, et al, 2013: Insulin resistance and inflammation markers in myocardial infarction. J. Inflamm. Res. 6: 83-90.

Gunaid, AA, Assabr AM, 2008: Prevalence of type 2 diabetes and other cardio-vascular risk factors in a semirural area in Yemen. East. Mediterran. Hlth. J. 14: 99-102.

Inoue, M, Iwasaki, M, Otani, T, et al, 2006: Diabetes Mellitus and the risk of cancer: results from a large-scale population-based cohort study in Japan. Arch. Intern. Med. 166:1871-7.

Kawasaki, E, Awata, T, Ikagami, H, et al, 2006: Systemic search for single nucleotide polymerphisms in a lymphoid tyrosine phosphatase gene (PTPN22): association betweena promoter polymerphism and type 1 diabetes in Asian populations. Am. J. Med. Genetics 140, 6: 586-93.

Matthews, DJ, Hoskers, JP, Rudenski, AS, et al, 1985; Homeostasis model assessment: Insulin resistance and $\beta$-cell function from fasting plasma glucose and insulin concentrations in man. Diabetologia 28:412-9.

Melmed, S, Polonsky, KS, Larsen, PR, Kronenbergm HM, 2011: Williams' Textbook of Endocrinology. Philadelphia: Elsevier/Saunders Metwalley, KA, El-Saied, AR, 2014: Thyroid abnormalities in Egyptian children and adolescents with type 1 diabetes mellitus: A single center study from Upper Egypt. Indian J. Endocrinol. Metab. 18, 5:637-41.

Oetting, A, Yen, PM, 2007: New insights into thyroid hormone action. Best Pract. Res. Clin. Endocrinol. Metab. 21:193-9.

Peeters, EY, Shabana, WM, Verbeek, PA, Osteaux, MM, 2003: Use of a curved-array transducer to reduce interobserver variation in sonographic measurement of thyroid volume in healthy adults. J. Clin. Ultrasound. 31:189-94. 
Rapoport, B, Chazenbalk, GD, Jaume, JC, et al, 1998: The thyrotropin (TSH) receptor: interaction with TSH and autoantibodies. Endocrinol. Rev. 19:673-716.

Rapp, K, Schroeder, J, Klenk, JA, et al, 2006: Fasting blood glucose and cancer risk in a cohort of more than 140.000adults in Austria. Diabetologia 49:945-52.

Rezzonico, J, Rezzonico, M, Pusiol, E, et al, 2008: Introducing the thyroid gland as another victim of the insulin resistance syndrome. Thyroid 18:461-4.

Riedemann, J, Macaulay, VM, 2006: IGF1R signaling and its inhibition. Endocrinol. Cancer 13, 1:S33-43.

Villano, MJB, Huber, AK, Greenberg, DA, et al, 2009: Autoimmune thyroiditis and diabetes: dissecting the joint genetic susceptibility in a large cohort of multiplex families. J. Clin. Endocrinol. Metabol. 94, 4:1458-66.

Yu, Q, Gao, F, Ma, XL, 2011: Insulin says NO to cardiovascular disease. Cardiovasc. Res. 89: 516-24.

Zou, Y, Ding, G, Lou, X, et al, 2013: Factors influencing thyroid volume in Chinese children. Eur. J. Clin. Nutr. 67, 11:1138-41. 